\title{
Antidepressant treatment for chronic depressed patients should not be discontinued prior to anesthesia
}

\author{
[Le traitement antidépresseur ne devrait pas être interrompu avant l'anesthésie de \\ patients atteints de dépression chronique]
}

Akira Kudoh MD, ${ }^{*}$ Hiroshi Katagai $\mathrm{MD}, \dagger$ Tomoko Takazawa MD $\dagger$

Purpose: To investigate whether antidepressants administered to patients for chronic depression patients should be continued or discontinued before anesthesia.

Results: We studied 80 depressed patients who were scheduled to undergo orthopedic surgery under general anesthesia. The patients were divided randomly into two groups; patients in Group A $(n=40)$ continued antidepressants before surgery and patients in Group B $(n=40)$ discontinued antidepressants $72 \mathrm{hr}$ before surgery. Two (5\%) out of 40 patients in Group A and eight (20\%) out of 40 patients in Group B had deterioration of depressive symptoms $(P=0.04)$. Delirium or confusion during the perioperative course occurred in five patients (13\%) in Group A and in 12 (30\%) in Group B ( $P=0.05)$. There were no significant differences in incidence ( 5 vs $6 \%$ ) of hypotension and arrhythmias during anesthesia between the two groups.

Conclusion: Antidepressants administered to depressed patients should be continued before anesthesia. Discontinuation of antidepressants did not increase the incidence of hypotension and arrhythmias during anesthesia, but increased symptoms of depression and delirium or confusion.

Objectif : Vérifier si le traitement antidépresseur administré aux patients atteints de dépression chronique devrait être ou non interrompu avant l'anesthésie.

Méthode : Nous avons étudié 80 patients déprimés qui devaient subir une intervention orthopédique sous anesthésie générale. Les patients ont été répartis au hasard en deux groupes: ceux du groupe $\mathrm{A}$ ( $n=$ 40) ont poursuivi le traitement antidépresseur jusqu'à l'opération et ceux du groupe $B(n=40)$ l'ont interrompu 72 h avant.

Résultats : Deux (5\%) patients du groupe A et huit (20\%) du groupe $B$ ont subi une détérioration des symptômes dépressifs ( $P=$ $0,04)$. Le délire et la confusion ont été observés chez cinq patients pendant la période périopératoire (13\%) chez les patients du groupe A et chez douze patients du groupe $B(30 \%)(P=0,05)$. II n'y a pas eu de différence intergroupe significative quant à l'incidence ( 5 vs $6 \%$ ) d'hypotension et d'arythmie pendant l'anesthésie.

Conclusion : Le traitement antidépresseur administré aux patients déprimés devrait se poursuivre avant l'anesthésie. Son arrêt n'augmente pas l'incidence d'hypotension ou d'arythmie pendant l'anesthésie, mais accentue les symptômes dépressifs, le délire ou la confusion.

$\mathrm{T}$ HE proportion of patients taking antidepressants who undergo surgery is reported to be $35 \%{ }^{1}$ Antidepressants may interact with anesthetics or affect mental condition postoperatively. The question as to whether the antidepressants should be discontinued preoperatively remains controversial. Antidepressants initially increase noradrenergic synaptic activity, thereby promoting arrhythmogenesis, but their chronic administration ultimately results in a decrease in noradrenergic transmission due to down regulation of B-adrenergic receptors. ${ }^{2}$ Chronic administration of antidepressants can cause hypotension, decreased myocardial contractility and sudden death. ${ }^{3}$ Patients taking antidepressants were shown to have increased susceptibility to cardiac arrhythmias during anesthesia. ${ }^{4,5}$ Sprung et al. ${ }^{6}$ reported that a patient who had received antidepressant therapy for six years experi-

From the Departments of Anesthesiology, Hakodate Watanabe Hospital, ${ }^{*}$ and Hirosaki National Hospital, † Hirosaki, Aomori, Japan. Address correspondence to: Dr. Akira Kudoh, Department of Anesthesiology, Hirosaki National Hospital, 1 Tominocho, Hirosaki 036-

8545, Aomori, Japan. Phone: 81-172-33-5111; Fax: 81-172-39-5112.

Accepted for publication September 10, 2001.

Revision accepted October 31, 2001. 
enced hypotension resistant to phenylephrine, ephedrine and dopamine treatment after induction of anesthesia and only a large dosage of norepinephrine was effective. Antidepressants possess moderate anticholinergic effects. Berggren et al. ${ }^{7}$ reported that the most important predictor for postoperative mental confusion was regular use of drugs with anticholinergic effects. Chung et al. ${ }^{8}$ have reported the possible interaction of antidepressants and general anesthesia as a cause of postoperative delirium. On the other hand, the withdrawal of antidepressants produces anxiety, agitation and depressed mood. ${ }^{9}$

As some reports indicate that chronic treatment with antidepressants can lead to blood pressure fluctuations, tachycardia and arrhythmias, it has been recommended that antidepressant use should be discontinued $72 \mathrm{hr}$ before surgery. $5,6,10,11$ However, there is little prospective work to show whether antidepressants should be continued or discontinued. The purpose of this study was to compare perioperative complications in patients who continued or discontinued antidepressants before surgery in depressed patients on chronic antidepressant therapy.

Patients and methods

The study was approved by the Medical Ethics Committee of our Institution. Informed consent was obtained from all patients. We studied 80 patients ranging in age from 35 to $63 \mathrm{yr}$ who were diagnosed as having major depression according to the Diagnostic and Statistical Manual of Mental Disorders, $\left(4^{\text {th }}\right.$ Ed.) criteria ${ }^{2}$ and 40 patients ranging in age from 30 to $64 \mathrm{yr}$ selected randomly as the control (Group C). All depressed patients were taking antidepressant drugs (imipramine, clomipramine, maprotiline and mianserin) for over a year. The state of depression was estimated quantitatively two days before and four days after surgery by means of the Hamilton depression score. ${ }^{13}$ The Hamilton depression scale is a useful, standardized questionnaire method to measure symptoms of depression. The questionnaire consists of 21 items with a cumulative scoring system based on questions about symptoms that are common in depression, such as sleep disturbance, weight change, fatigue factors, sexual dysfunction and cognitive components of depressive illness. All patients had orthopedic surgery including elective reduction of arm or lower limb fracture under general anesthesia at Hakodate Watanabe Hospital and Hirosaki National Hospital between 1997-2001. Depressed patients were divided randomly into two groups; patients in Group A ( $n=40)$ continued antidepressants before surgery and patients in Group B

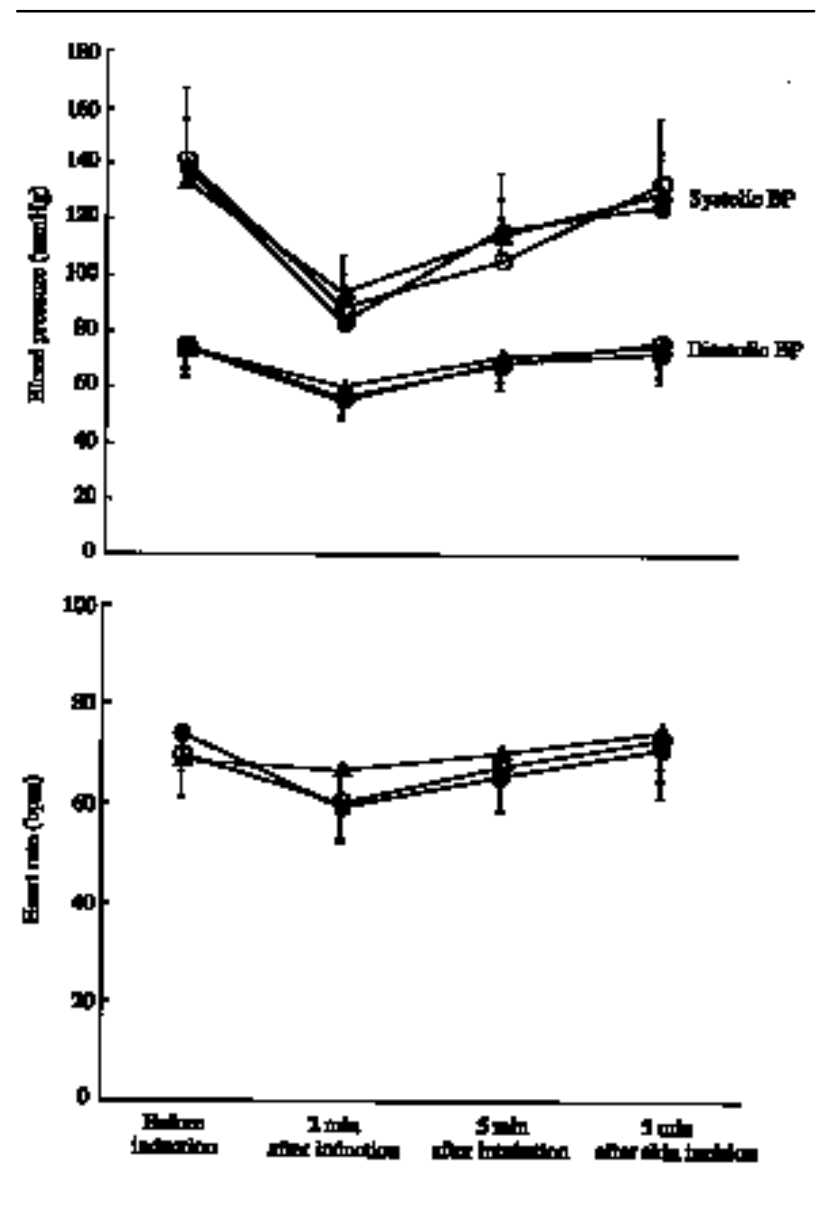

FIGURE Full circles=Group A; open circles=Group B; triangles=Group C.

( $n=40)$ discontinued antidepressants $72 \mathrm{hr}$ before surgery. The antidepressants were resumed on the day after surgery. Randomization was based on computergenerated codes. Patients with a history of cardiovascular disease, respiratory disease, alcohol abuse, markedly abnormal preoperative serum sodium, potassium or glucose concentration (sodium $<130$ or $>150 \mathrm{mmoL} \cdot \mathrm{L}^{-1}$, potassium $<3.0$ or $>6.0 \mathrm{mmoL} \cdot \mathrm{L}^{-1}$, and glucose $<60$ or $>300 \mathrm{mg} \cdot \mathrm{dL}^{-1}$ ) were excluded.

Anesthesia was induced with $1.5 \mathrm{mg} \cdot \mathrm{kg}^{-1}$ of iv propofol, at an infusion rate of $0.75 \mathrm{mg} \cdot \mathrm{kg}^{-1} \cdot \mathrm{min}^{-1}$, and $2 \mu \mathrm{g} \cdot \mathrm{kg}^{-1}$ fentanyl. Tracheal intubation was facilitated with vecuronium $0.1 \mathrm{mg} \cdot \mathrm{kg}^{-1}$ intravenously. For the maintenance of anesthesia, $1.5-2.0 \%$ isoflurane in nitrous oxide $(70 \%)$ and oxygen was administered according to clinical criteria. Electrocardiography (ECG), arterial blood pressure, inspiratory oxygen and end-expiratory carbon dioxide concentrations 
TABLE I Demographic and perioperative valuables

\begin{tabular}{|c|c|c|c|}
\hline & Group $A$ & Group B & Group C \\
\hline Number of patients & 40 & 40 & 40 \\
\hline Age (yr) & $49.5 \pm 9.4$ & $50.5 \pm 7.9$ & $51.9 \pm 7.1$ \\
\hline Weight (kg) & $52.6 \pm 13.3$ & $53.0 \pm 15.0$ & $53.5 \pm 11.8$ \\
\hline Duration of surgery $(\mathrm{min})$ & $107.3 \pm 34.0$ & $112.7 \pm 37.4$ & $117.3 \pm 33.6$ \\
\hline Duration of anesthesia ( $\mathrm{min}$ ) & $141.1 \pm 42.4$ & $146.0 \pm 47.1$ & $134.5 \pm 35.0$ \\
\hline Blood loss (g) & $123.1 \pm 37.2$ & $111.9 \pm 34.0$ & $128.0 \pm 30.6$ \\
\hline Total fentanyl consumption $(\mu \mathrm{g})$ & $376.2 \pm 30.7$ & $355.4 \pm 29.0$ & $365.8 \pm 10.4$ \\
\hline \multicolumn{4}{|l|}{ Antidepressants } \\
\hline Imipramine & $13(33 \%)$ & $15(38 \%)$ & \\
\hline Clomipramine & $5(13 \%)$ & $6(15 \%)$ & \\
\hline Maprotiline & $12(30 \%)$ & $11(28 \%)$ & \\
\hline Mianserin & $10(25 \%)$ & $8(20 \%)$ & \\
\hline
\end{tabular}

$\left(\right.$ EtCO $\left.\mathrm{C}_{2}\right)$, nasopharyngeal temperature, transcutaneous oxygen saturation were monitored throughout the anesthesia period using a 5250 RGM analyzer (Ohmeda, Madison, USA). Acetated Ringer's solution was infused at a rate of $5 \mathrm{~mL} \cdot \mathrm{kg}^{-1} \cdot \mathrm{hr}^{-1}$ to all patients. The lungs were ventilated mechanically to maintain the $\mathrm{EtCO}_{2}$ at $35-40 \mathrm{mmHg}$. During the operative procedure, the nasopharyngeal temperature was monitored continuously with an electric thermistor and maintained at $36.0-37.0^{\circ} \mathrm{C}$ using a warming blanket and control of the temperature in the operating room. Postoperatively, all patients were treated with a nonsteroidal analgesic (diclofenac sodium $50 \mathrm{mg}$ suppository) every six hours for incisional pain.

ECG was recorded during the induction of anesthesia and blood pressure was recorded every minute until $15 \mathrm{~min}$ after induction and every five minutes subsequently.

Postoperative confusion was assessed using the confusion assessment method (CAM), which has been shown to be a sensitive and reliable method for assessment of confusion. ${ }^{14}$ The patients were examined at least once daily with the CAM diagnostic criteria for confusion until the seventh day after operation and the assessment of confusion was performed whenever a patient was found to be changed mentally by the nursing staff. The nurses were not aware of the purpose of the study.

Pain scores were evaluated by nurses every eight hours for the first $24 \mathrm{hr}$ after the end of operation and every 24 $\mathrm{hr}$ after that time. Pain was estimated using a $100-\mathrm{mm}$ visual analogue scale (VAS; $0 \mathrm{~mm}$ representing no pain and $100 \mathrm{~mm}$ representing the worst imaginable pain).

Data are expressed as mean \pm standard deviation. Comparisons between groups in VAS pain score, blood pressure, heart rate, mean duration of anesthesia and surgery and mean volume of blood loss were analyzed by repeated-measures ANOVA followed by using
Bonferroni's correction. Comparison of the Hamilton depression scale before and after the operation was analyzed by ANOVA followed by using Dunnett's test. Incidence of psychosis emergence or confusion was analyzed by Chi-square testing. $P$ values less than 0.05 were considered significant.

Results

There were no significant differences in age, average weight, mean duration of anesthesia and surgery, mean volume of blood loss and total fentanyl consumption between the three groups (Table I). In this study, no patient had severe complications throughout the postoperative course. There were no clinically significant differences in the postoperative pain scores between the three groups for three days after the operation.

Two (5\%) patients out of 40 in Group A and two (5\%) patients out of 40 in Group B developed arrhythmias. The arrhythmias consisted of ventricular ectopic rhythm and returned to sinus rhythm without any treatment. There were no patients who presented an abnormal QRS width on the ECG in the three groups throughout the perioperative period.

In the preoperative period, two patients in Group A and two patients in Group B had postural hypotension. Hemodynamic changes immediately following induction of anesthesia were observed in both study groups. Three ( $8 \%$ ) patients in Group A and two (5\%) patients in Group B had episodes of hypotension (systolic blood pressure less than $70 \mathrm{mmHg}$ during induction). Ephedrine and infusion of acetated Ringer's solution were effective for all patients who developed hypotension. There were no arrhythmias when ephedrine was administered. There were no hemodynamic differences in mean systolic, diastolic blood pressure and heart rate before induction, two minutes after induction, five minutes after intubation and five minutes after skin incision between groups A and B. 
TABLE II Incidence of hypotension and arrhythmias

\begin{tabular}{llll}
\hline & Group A & Group B & Group C \\
\hline $\begin{array}{l}\text { Hypotension during anesthesia } \\
\text { (less than 70 mmHg) }\end{array}$ & $3(8 \%)$ & $2(5 \%)$ & $0(0 \%)$ \\
Arrhythmias during anesthesia & $2(5 \%)$ & $2(5 \%)$ & $1(3 \%)$ \\
\hline
\end{tabular}

TABLE III Pain score after surgery

\begin{tabular}{llll}
\hline & Group A & Group B & Group C \\
\hline VAS pain score POD 1 & $20.2 \pm 7.8$ & $23.6 \pm 9.0$ & $24.8 \pm 7.1$ \\
VAS pain score POD 2 & $17.4 \pm 8.1$ & $17.0 \pm 7.5$ & $18.5 \pm 5.9$ \\
VAS pain score POD 3 & $11.7 \pm 6.1$ & $10.8 \pm 5.2$ & $12.3 \pm 4.6$ \\
\hline
\end{tabular}

VAS=visual analogue scale; $\mathrm{POD}=$ postoperative day.

TABLE IV Incidence of delirium or confusion

\begin{tabular}{|c|c|c|c|c|}
\hline & Group $A$ & Group B & Group C & $P$ values \\
\hline $\begin{array}{l}\text { The day before the } \\
\text { operation }\end{array}$ & $0(0 \%)$ & $0(0 \%)$ & $0(0 \%)$ & $P=\mathrm{NS}$ \\
\hline $\begin{array}{l}\text { The day of the } \\
\text { operation }\end{array}$ & $0(0 \%)$ & $6(15 \%)$ & $0(0 \%)$ & $P=0.01$ \\
\hline \multicolumn{5}{|l|}{ Postoperative day } \\
\hline 1 & $1(3 \%)$ & $4(10 \%)$ & $0(0 \%)$ & $P=\mathrm{NS}$ \\
\hline 2 & $4(10 \%)$ & $2(5 \%)$ & l $(3 \%)$ & $P=\mathrm{NS}$ \\
\hline 3 & $0(4 \%)$ & $0(0 \%)$ & $0(0 \%)$ & $P=\mathrm{NS}$ \\
\hline Total & $5(13 \%)$ & $12(30 \%)$ & $1(3 \%)$ & $P=0.05$ \\
\hline
\end{tabular}

Two (5\%) patients in Group A and in eight (20\%) patients in Group B increased their Hamilton depression scale after surgery by five points or more $(P=0.04)$. Thirty $(75 \%)$ patients in Group A had an unchanged or decreased Hamilton depression score after surgery. On the other hand, 21 (53\%) patients in Group B had a stable or decreased Hamilton depression score after surgery $(P=0.04)$. The mean Hamilton depression score was $13.7 \pm 4.9$ for Group A and 12.5 \pm 6.2 for Group B two days before surgery and was $14.2 \pm 7.1$ for Group A and $14.8 \pm 6.0$ for Group B four days after surgery $(P=\mathrm{NS})$. Derilium or confusion for the first postoperative three days occurred in five (13\%) patients of Group A and in $12(30 \%)$ patients of Group B $(P=0.05)$. The peak incidence of derilium or confusion was on the day of surgery in groups A and B (Table IV). In this study, there was no relationship between age and derilium or confusion $(P=0.72)$.

Discussion

Previous authors have discussed the problems associated with providing anesthesia to patients taking antidepressants. ${ }^{5,6,10}$ Arrhythmias, hypotension and postoperative delirium have been reported. . $^{5,8,10}$
Some clinicians believe that the antidepressants should be discontinued approximately three days before general anesthesia because of adverse intraoperative responses. $5,6,10,11$ In this study, five $(6 \%)$ out of 80 patients presented hypotension. No patient with severe hypotension was resistant to vasopressor therapy. Five percent of depressed patients developed arrhythmias and returned to sinus rhythm without any treatment. The incidence of hypotension and arrhythmias was not different between patients who continued or discontinued antidepressants. Cardiovascular side effects are rare when antidepressants are taken in therapeutic dosages. ${ }^{15}$ Four patients presented postural hypotension preoperatively and developed hypotension during the induction of anesthesia. Postural hypotension may herald the need for greater caution during the induction of anesthesia in patients on chronic therapy with antidepressants. The American Heart Association's recommendations for managing hypotension resulting from antidepressants is to first administer $\mathrm{l} \mathrm{L}$ of $i v$ saline. If this fails, the next step is to increase the serum $\mathrm{pH}$ to $7.5-7.55 .{ }^{16}$ As a directacting vasopressor can produce a dangerously increased vasopressor response in patients treated by antidepressants, ${ }^{17}$ an indirect-acting vasopressor would be an appropriate treatment. In this study, serum $\mathrm{pH}$ was normal in all patients. Infusion of acetated Ringer's solution and ephedrine were effective in all patients who developed hypotension. Previous reports indicated in animal studies that chronic treatment with antidepressants led to tachycardia and arrhythmias. ${ }^{5,6,10}$ This discrepancy may, possibly, be explained by a species difference in the arrhythmogenic sensitivity to antidepressants, because arrhythmogenic sensitivity to catecholamine differs between animals and humans. ${ }^{18}$

The incidence of patients who increased their Hamilton depression score postoperatively was higher in patients who discontinued antidepressants before anesthesia. In addition, the incidence of patients who presented a stable or decreased Hamilton depression score was lower in patients who discontinued antidepressants. Thus, discontinuation of antidepressants appears to increase depressive symptoms postoperatively.

Acute confusion or delirium after surgery has been associated with adverse clinical and economic outcomes, including high rates of complications, poor functional recovery, increased length of stay and high costs. ${ }^{19}$ Administration of antidepressants is one of the causes of postoperative confusion. ${ }^{8}$ On the other hand, discontinuation of antidepressants carries the risk of anxiety, agitation and recurrent depression. The present study shows that discontinuation of antide- 
pressants before anesthesia increases the incidence of delirium or confusion. The peak incidence of delirium or confusion was on the day of surgery in Groups A and $\mathrm{B}$, similar to the timing of withdrawal symptoms that occur one to two days after the last administration of antidepressants. ${ }^{9}$ Several factors are involved in the development of postoperative delirium including hypoxia, age, postoperative pain and medication as well as psychological disorder. ${ }^{19}$ In this study, there were no patients who developed hypoxia and no differences in age and postoperative pain scores between the three groups for three days after the operation.

In summary, the incidence of intraoperative hypotension and arrhythmias was low in patients on chronic antidepressant therapy, whether treatment was ceased preoperatively or not. On the other hand, discontinuation of antidepressants was associated with an increased incidence of delirium, confusion and depressive symptoms. We conclude that antidepressant treatment for chronically depressed patients should not be discontinued prior to anesthesia.

\section{References}

1 Scher CS, Anwar M. The self-reporting of psychiatric medications in patients scheduled for elective surgery. J Clin Anesth 1999; 11: 619-21.

2 Braverman B, McCarthy RJ, Ivankovich $A D$. Vasopressor challenges during chronic MAOI or TCA treatment in anesthetized dogs. Life Sci 1987; 40: 2587-95

3 Anonymous. Drugs for psychiatric disorders. Med Lett Drugs Ther 1991; 33: 43-50.

4 Edwards RP, Miller RD, Roizen MF, et al. Cardiac responses to imipramine and pancuronium during anesthesia with halothane or enflurane. Anesthesiology 1979; 50: 421-5.

5 Glisson SN, Fajardo L, El-Etr AA Amitriptyline therapy increases electrocardiographic changes during reversal of neuromusclar blockade. Anesth Analg 1978; 57: 77-83.

6 Sprung J, Schoenwald PK, Levy P, Krajewski LP. Treating intraoperative hypotension in a patient on long-term tricyclic antidepressants: a case of aborted aortic surgery. Anesthesiology 1997; 86: 990-2.

7 Berggren D, Gustafson Y, Eriksson B, et al. Postoperative confusion after anesthesia in elderly patients with femoral neck fractures. Anesth Analg 1987; 66: 497-504.

8 Chung F, Meier R, Lautenschlager E, Carmichael FJ, Chung A. General or spinal anesthesia: which is better in the elderly? Anesthesiology 1987; 67: 422-7.

9 Dilsaver SC, Coffman JA Antipsychotic withdrawal phenomena in the medical-surgical setting. Gen Hosp
Psychiatry 1988; 10: 438-46.

10 Wong KC, Puerto AX, Puerto BA, Blatnick RA Influence of imipramine and pargyline on the arrhythmogenicity of epinephrine during halothane, enflurane or methoxyflurane anesthesia in dogs. Life Sci 1980; 27: 2675-8.

11 Janowsky EC, Risch C, Janowsky DS. Effects of anesthesia on patients taking psychotropic drugs. J Clin Psychopharmacol 1981; 1: 14-20

12 American Psychiatric Association. Diagnostic and Statistical Manual of Mental Disorders, 4th ed. Washinton DC: Am Psychiatric Assoc 1994: 458-62.

13 Hamilton M. A rating scale for depression. J Neurol Neurosurg Psychiatry 1960; 23: 56-61.

14 Innouye SK, van Dyck CHV, Alessi CA, Balkin S, Siegal $A P$, Horwitz RI. Clarifying confusion: the confusion assessment method. A new method for detection of delirium. Ann Internal Med 1990; 113: 941-8.

15 Cummins RO Textbook of Advanced Cardiac Life Support. Dallas, American Heart Association, 1994.

16 Rosenthal JA American Heart Association recommendation for treating tricyclic antidepressant-induced hypotension (Letter). Anesthesiology 1997; 87: 1259-60.

17 Harding S, Jones RM Intercurrent medication. In: Aitkenhead AR, Jones RM (Eds.). Clinical Anaesthesia. New York: Churchill Livingstone Inc., 1996: 91-105.

18 Sumikawa K, Ishizaka N, Suzaki M. Arrhthmogenic plasma levels of epinephrine during halothane, enflurane, and pentobarbital anesthesia in the dog. Anesthesiology 1983; 58: 322-5.

19 Murray AM, Levkoff SE, Wetle TT, et al. Acute delirium and functional decline in the hospitalized elderly patients. J Gerontol 1993; 48: M181-86. 